\title{
I-Reflexes: The Affective Implications of Bodies in Dance Improvisation Performance
}

\section{Cover Page Footnote}

Acknowledgements I want to thank composer and musician Martin Devek and sonic artist Tristan Clutterbuck for their enthusiasm, ideas and time put in this project. I am grateful to my supervisors Dr Aoife McGrath and Dr Paul Stapleton for their ongoing commitment to my doctoral project. I want to thank Johannes Birringer for inviting us to perform I-Reflexes at the International Meta-Body Symposium 2016, to the curator of the JamJar series, Una Monaghan, and to the team at the R-Space Gallery (Lisburn) for hosting this piece. The research for this article was funded by the Department of Employment and Learning of Northern Ireland. 


\section{Introduction}

In this article, I present - from the perspective of the dance improviser-an analysis of my practice-as-research project, entitled I-Reflexes. In this piece I explore factors influencing decision-making in dance improvisation performance. I-Reflexes captures the improvisational interaction of three performers: a solo dancer, a musician, and a sonic artist; the audience also participates through the mediation of their mobile phones. As the choreographic improvisation and original music composition evolves and loops, the soundscape of improvisation created between the audience and the musicians' interaction merges, thus proposing new dynamics of movement for the dancer. In this performance project, ringtones trigger unplanned, reflex-like movements in the body, suggesting alternate terms of decision-making within dance improvisation practice.

I-Reflexes evolved from my curiosity regarding the spontaneous physical reactions to sounds emitted from communication devices, and my observation of others' physical reactions to ringtones. I then considered the involvement of conscious awareness in this process, and how pre-set sounds may trigger an action response as bodily reflex. This phenomenon suggested the title I-Reflexes: a metaphor to explore the contemporary social phenomena of unintentional attention response to sounds coming from mobile devices. The idea for including participation through the use of ringtones was aimed at emulating and exaggerating the reality of mobiles phones in western societies; the original aim was to explore the relationship between auditory stimuli and decision-making in dance improvisation performance. My objective became to develop a performance that would offer me a dynamic and stimulating context, one in which the stimuli were arbitrary and random in each encounter. Since most of the research would emerge from the performance experience itself, I facilitated a multiplicity of experiences that would allow me to investigate a wider spectrum of interactive participation in dance improvisation performance.

I discovered, however, that my affective experience in relation to the audience influenced my dance improvisation in ways that I had not anticipated: the audience's gestures, bodily engagement with the performance and the interaction among audience members took my attention. As a result, early in the project, the concept of affect emerged as a significant concept for investigating decision-making in dance improvisation. Affect theory seemed a fruitful approach with which to reflect upon the 
relational dynamic between dance improvisers and audience participation, and how this relation influences decision-making within improvisational performance.

In his article, I will adopt-within the parameters of affect theory-the perspective of an embodied meaning-making framework, as developed by social psychologist Margaret Wetherell. The concepts offered in her model provide a theoretical ground for understanding the intrinsically somatic and communicative nature of dance improvisation practice. In addition, I suggest that kinesthetic empathy is a key concept for examining the corporeal communication between dance improvisers and their audience. The concept of kinesthetic empathy refers to the ability to experiencing somebody else's movement experience, emotionally and even viscerally. Thinking in terms of the affective implications of kinesthetic empathy is a fertile approach to studying dance improvisation, since bodily communication is the primary medium of interaction. Due to this interconnectedness between perceptual and affective processes in dance improvisation, I suggest, to advance understandings of this practice and theory, that perception and affect should be explored together.

Drawing on the experience of performing I-Reflexes, together with my critical reflection, I propose that the act of perception brings the world into the body of the improviser, while the physical experience of affect places the body in relation to other bodies in the world. My analysis will be centered upon my perception and affective experience of the corporeal and expressive gestures of the audience in the performance situation created in I-Reflexes. An important discovery that emerged from this performance project was that proxemics in dance improvisation performance is a factor that has the capacity to influence the dance improviser's decision-making process in the flow of the moment. Most significantly, this research project will advance the argument that interactive participation in dance improvisation performance creates a closer affective encounter between performers and participants, connecting them in a stimulating way.

\section{An Affective Approach for the Study of Dance Improvisation}

Dance improvisation involves the practice of paying attention to the dancing body. Through training, dance improvisers develop the ability to guide their attention to specific sensations in the body, acquiring a sensitivity towards sensing and perceiving the body, space and surrounding objects. This practice of attention developed in dance improvisation practice involves narrowing the dancer's field of 
awareness. At the start of her dance, the improviser pre-determines where she will place her attention. This is often a flexible process. Movement invitations are sought from within this responsiveness to the sensing body. In this process of attending to sensations and experiences as they happen in the flow of dancing, the improviser may use a question to interrogate her experience. Questions are used to activate and prompt a deeper body-mind connection. This practice of interrogation is unique to each improviser, reflecting a specific concern or curiosity. This practice of attention and questioning through dancing is the core of what makes dance improvisation both a skillful practice and a research methodology.

In my dance improvisation practice, I have been influenced by the work of Australian choreographer Rosalind Crisp. She questions her dancing by asking: "What keeps me interested?"; "What am I paying attention to?;" :What do I warm up for?;" "How do I know that I'm not sleeping?" By engaging with these questions in my own improvisation practice, I found that I was experiencing spaces and events (and all they contain) as affective encounters. I noticed that my affective experience was allpervading throughout my experience of dancing, informing movement choices as well as aesthetic decisions. In paying attention to this undercurrent of bodily sensations, I soon became aware of the influence that affective experiences have on my body dispositions and readiness towards movement.

From the perspective of affect, I placed my attention on the exchange of affective states and movement qualities in the dancing. For example, attending to the experience of speed, rhythms and vibrations in my body in a particular moment became a strategy for starting an improvisation. Sensing the bodily sensation of a given affective experience might direct my attention to a body part as a starting place for movement. When developing I-Reflexes, I dance-improvised to recordings of sounds from my everyday environment, moving both open-eyed and, at other times, blindfolded. I restricted my movement choices to selectively moving upper or lower limbs, as well as at other times experimenting with fixed positions: sitting, standing, lying down. Each experience was intense at an affective level. After rounds of thirty minutes of moving to sounds, I felt emotionally drained; my auditory system felt saturated. This experience suggests a close connection between the perceptual system and affective processes.

My initial thinking around the notion of reflex was that the impulsiveness of my movement would detach me from my conscious awareness, and that I would no longer 
produce a truthful (to myself) aesthetic movement expression in response to the ringtones. The ideas on reflex-as a two-way response and interaction with the worldfrom philosopher Maurice Merleau-Ponty_gave me a deeper insight into how to think about this stimuli-response phenomenon. Merleau-Ponty writes:

Reflexes themselves are never blind processes: they adjust to the "sense" of the situation, they express our orientation toward a "behavioural milieu just as much as they express the action of the "geographical milieu" upon us. [...] The reflex does not result from objective stimuli, it turns toward them, it invests them with a sense that they did not have when taken one by one or as physical agents, a sense that they only have when taken as a situation. ${ }^{1}$

Merleau-Ponty argues that reflex is not a passive response; rather, it is a two-way perceptual process. From this perspective, the dance improviser, in responding to signifiers (such as ringtones), brings together his/her artistic identity in the act of turning towards the stimulus in performance. From this understanding of reflex, I devised a question to interrogate my dance practice during the development of $I$ Reflexes: "Towards what objects am I turning towards when performing?" Whilst my original intention was to focus purely on auditory stimuli, during my first performance of I-Reflexes I noticed how my movement was affected by my evolving connection with the audience. Their gestures, such as laughter or nodding, pulled my attention away from a focus exclusively on sounds. This connection with the audience gestures occurred in I-Reflexes due to my physical proximity to the audience.

The first performance of I-Reflexes was at R-Space Gallery in Lisburn, Northern Ireland as part of the International Envisioning Weekend in March 2016. The performance space was an art gallery that could accommodate fifteen people. The initial idea was to have the audience sitting in the round, however we had to adapt to an endon seating area. Nevertheless, because of the size of the room and the natural daylight coming from three large windows, I could feel the immediacy of the audience's presence from any position in the performance area.

In the first iteration, I noticed how the audience's bodily gestures fed my dance improvisation choices. At the start of the piece, I sensed their expectancy as they watched me: my phone rang and I texted back. This was followed by a short pause (with only ambient room sound) that built up the atmosphere of surprise. Then all the phones in the room sounded together with a welcome text message. At this moment in the piece, I was sitting on a chair, observing the reactions of the audience. In this opening sequence, I experienced a sense of delight as I watched the expressions of 
wonder in their faces when they heard their phones ringing as part of a dance show. In this first performance (I-Reflexes, March, 2016), the audience members looked around before answering their phones, almost as if asking for permission to check their phones. This response was spontaneous; I perceived it as an expression of surprise.

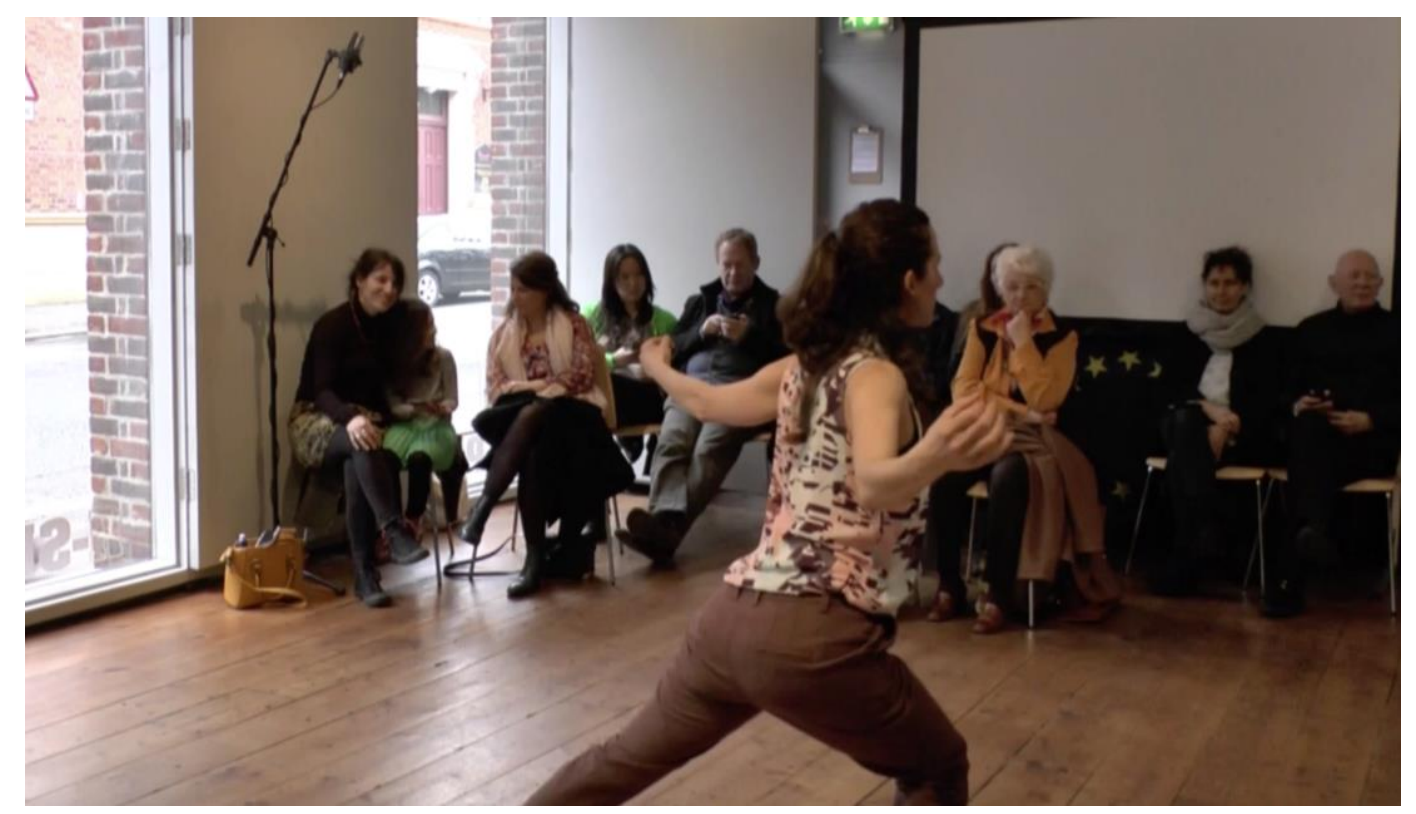

Figure 1. I-Reflexes, R-Space Gallery, Lisburn March 2016.

In this transgression of pre-established rules for a performance event, I sensed-in the group's physical action - a sort of curiosity and playfulness that affected my movement disposition. This first moment of active engagement was intended as a way of allowing the audience to experience their physical and affective relationship to their phones. The intimate performative situation created in this first encounter with the audience pointed towards proxemics as an important factor in this work. Moreover, because of the intimacy of the performative event, I-Reflexes resembled an ordinary circulation of affect.

Margaret Wetherell describes the movement of affect in social practices via the concept of "pulses of energetic relation." She employs this concept to describe how affective experiences are negotiated between bodies in the everyday. Wetherell is interested in the "rapid, implicit and explicit, negotiation processes through which we jointly begin to figure the affective moment we are in, and what should happen next."3 In everyday situations, such encounters have the capacity to affect us in meaningful ways; the affective encounter changes and transforms us in both subtle and powerful ways. Wetherell's approach locates affect in the body, as well as in the flow of ordinary life events. This suggest that affect is not just a property of bodies but it is found within 
social encounters, events and structures. She defines affect as involving sense and sensibility, encompassing the complexity of the contrasting nature of affective phenomena: on the one hand, the embodied flow of the pre-reflective and nonconscious sensory experience; and on the other, the organized, recursive processes and flexible orderings of conscious responses that facilitate social practices. ${ }^{4}$ By thinking of affect in terms of sense and sensibility, I gained a deeper understanding of the relational processes that took place in I-Reflexes. This analogy between an everyday situation of affective communication and the affective encounter of bodies in I-Reflexes points towards how the proximity between improvisers and audience has the potential to affect the dancer's decision-making process in the flow of dancing.

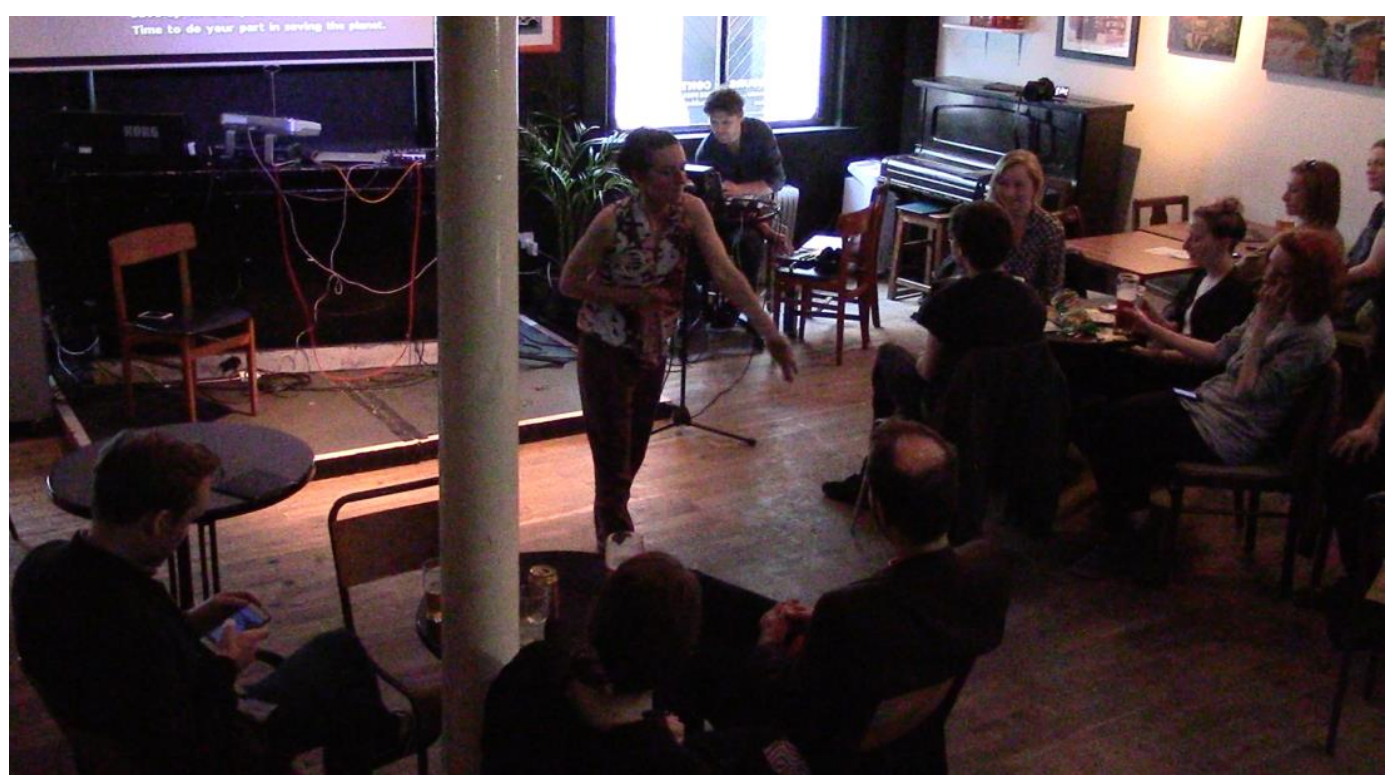

Figure 2. I-Reflexes at JamJar, Black Box May 2016.

The role of proxemics was a significant factor in my improvisation in the final show. We performed I-Reflexes at JamJar, an event for female improvisers at the Black Box bar space in Belfast, Northern Ireland (May 2016). On this occasion, the audience sat in a cabaret-style room, and the performance area was a small space in the center. My proximity to the audience was inescapable; many times I felt as if my movements were entering their private space. This time, not only the audience's physical actions of reaching for their phones affected my movement choices, but also other casual movements such as lifting a drinking glass. Their affective engagement with the performance, along with the closeness between myself and the audience, produced in me the desire to transgress some pre-established performance codes. For example, I felt an urge to interact with objects that were on tables and to get into contact with 
participants as if they also were performers. In contrast to the first performance, this time it wasn't so much the audience's gestures that influenced my dance improvisation but the venue-being in a bar pushed my desired for movement out of the arbitrary delimited performance area. Perhaps because the performance area was loosely defined around a space between a wooden platform and bar tables, my perceptual boundary was also extended to involve objects and situations outside of my dancing body and its immediately surrounding area. In this performance, I felt that the intersubjective negotiation of energies and gestures was more evident to the audience, as they could easily trace my engagement with their actions as I moved closer, or away, from certain audience members.

Different ringtones were also elements influencing my perception of the audience. In the performance in R-Space, ringtones ranged from the popular I-Phone distinctive tune to a duck's quack-I linked this to the wide age range in the audience, including young children to older adults, which was unique to this particular show. There were some funny moments when the sound of a quack went off and I made a forward and back wobbling movement with my head. I took the loud laugh of the audience as a sign that they were attentively following the relationship between the soundscape and the movement. When receiving the final text message that closed the performance, the audience burst into a collective laugh — such responses did not occur in any of the other four shows. According to Wetherell, understanding any particular instance of circulation of affect involves "understanding a raft of processes." By this, she refers to processes such as "intersubjective negotiations"- this being the most relevant to my analysis, ${ }^{5}$ - as I wasn't taking the audience's feeling of amusement and re-enacting their laugh, for example, but instead I found that their feeling heightened my attention towards the action or movement that had initially caused their surprise. I came to think that the circulation of affect was between the audience, myself as a dancer and the performance. Wetherell suggests that in this instance of affective circulations within social practices, affect becomes 'supra-personal' or "transpersonal." "From this view, the performative event may be considered as the supra-personal body that contains the affective experiences of all in the room.

In the field of dance studies, this focus on the relational dynamics in dance improvisation is shared by dance scholar and improviser Susan Leigh Foster, who describes the sensing and meaning making process that defines dance improvisation practice in this way: 
This body, instigatory as well as responsive, grounds the development of consciousness as a hyperawareness of relationalities. Each next moment of improvising, full of possible positionings, develops its choreographic significance as all participants' actions work to bring the performance into proper proportion or relation. ${ }^{7}$

Building upon the notion of circulation of affect proposed by Wetherell, this idea of "hyperawareness of relationalities" points to the prominence of intersubjective negotiations in dance improvisation practice. Foster's description of the practice highlights the relational counterbalance between both leading and responding to stimuli during the improvisational event. Her account appreciates that in group improvisation, every dancer has the capacity to affect the others, creating balance in relations within the performance. Foster points to the proportion of such relations brought by the aggregation of factors in the improvisational experience, for example she talks about power circulating through collective action in dance improvisation. ${ }^{8}$ Foster's description of dance improvisation suggests a play of forces inside the performance situation. Extending this perspective to the context of interactive participation in dance improvisation performance suggests a counterbalance of affective forces that move within the performance event, pulsating between performers and audience, advancing and retrieving between bodies.

Foster offers an interesting view of how this relationship between bodies is negotiated in the dance improvisation event-she proposes that in improvisation "power can only keep on the move, running as fast as it can to partner, to empower performers, never overcoming them." "I take the concept of power as referring to the affective potential available in bodies, our capacity to affect and be affected by others. This idea of power as being on the move resembles the notion of the "supra-personal" nature of affective phenomena developed by Wetherell. Building upon Foster's and Wetherell's arguments, the relationship between bodies in improvisation performance can be thought of as an affective encounter, where affective forces can influence each other through the experience of movement and the perception of that movement in others. Both perspectives point towards the dynamic relationship between perceptive and affective process involved in social interactions. In addition, I suggest that considering the improvisational event as an affective encounter can be explained in terms of the supra-personal nature of affect proposed by Wetherell.

Foster also offers a reflection on the effect that watching improvised dance performance has on the audience: 
Improvisation empowers those who witness it as well as those who perform it. Watching improvisation, consciousness expands out of a passive reception of an event and towards active engagement in the actual making of the event. Viewers participate along with the performers in the open field of possible choices and the performers' construction and selection of those choices through which meaning is determined. ${ }^{10}$

She proposes that the viewer of dance improvisation is a co-maker, a concept that extends the agency of the dance to those in the audience. According to this view, the dance improviser is not a sole maker but she is joined by her audience in the creation of the dance. Moreover, this perspective of the practice also points towards the negotiation of affect between dancers and audience. This understanding of watching dance improvisation highlights the fact that being an audience member requires perceptual engagement, such as active seeing and listening; the viewer is already an active participant in its role of audience member. In I-Reflexes, incorporating a set task for the audience to enact aggregated an element that bridged different modes of doing in the performance situation. Through their actions and bodily gestures, the audience's affective engagement with the performance was exposed. In addition, because of the proximity between bodies, the audience's presence was heightened, which empowered their capacity to affect other bodies during the performance event.

Through this discussion, I have explored an improviser's perspective on some aspects of the experience of dance improvisation and audience participation in performance. Furthermore, this discussion highlights the effectiveness of the notion of affective encounter proposed by Wetherell as a useful concept to analyse the relationship between improvisers and audience members. Wetherell's framework for the study of affect within social practices offered me a critical framework for considering how the audience's gestures and actions in I-Reflexes influenced my own choices of movement and form. The relationship between affect and perception emerged as a deeply interconnected process requiring conjoined consideration. In order to explore the bodily communication experienced in I-Reflexes, I will now examine the concept of kinesthetic empathy in the context of dance improvisation performance, in order to explore the affective negotiation of meaning by means of corporeal communication. I will discuss the affective implications of kinesthetic empathy, with the purpose of establishing what these two concepts have to offer for examining the fluid affective space between bodies in improvisation in performance. 


\section{The Affective Implications of Kinesthetic Empathy in Dance Improvisation}

The concept of kinesthetic empathy has a long been explored in dance scholarship, starting from the work of John Martin ${ }^{11}$ who proposed the notion of "inner mimicry" or "kinesthetic sympathy" to refer to the motor experience and traces left on those watching the dance. Recent work by Susan Leigh Foster ${ }^{12}$ and Elizabeth Dempster ${ }^{13}$ on kinesthetic empathy provide new critical approaches to understand the nuances of the experience of watching dance. Broadly defined, kinesthetic empathy refers to the ability to sense the corporeality of other bodies and empathize with their bodily experience. In other words, it is not simply about registering movement, but it is about recognizing our own physical experience, in the experience of another. It is difficult to think how this relational experience between bodies - this responsiveness to the experience of moving bodies - can be detached from its affective implications. As suggested by Wetherell, sense, sensibility and meaning-making are all encompassed processes within the experience of living in a social world. Considering the affective implications of kinesthetic empathy highlights the fact that watching other bodies in movement has the capacity to produce changes in ourselves; generating new ways of sensing and experiencing, while also suggesting new meanings to our bodily experiences.

Research on affect and kinesthetic empathy has resurged as part of a paradigmatic shift towards embodied cognition research-across the sciences, arts and humanities. Although these two above-mentioned concepts are different and carry their own individual conceptual frameworks, they are related in terms of the sensing body and its capacity to impact others. Dance researchers are especially aware of the affective implications of the experience of kinesthetic empathy. Cultural scholars Dee Reynolds and Matthew Reason suggest that kinesthetic empathy is a significant intra-disciplinary concept that contributes to the study of the effects of human communication, especially through bodily expressions. ${ }^{14}$ Studies on kinesthetic empathy, however, tend to focus on the experience of the audience watching dance. Wetherell, in contrast, approaches the relationship between bodies using critical discourse analysis. Her embodied, meaning-making model focuses on the fluid exchange of affect in the flow of social life, producing rich and texturized analysis. She studies the embodied negotiation of meaning in situated practices from a broad understanding of discourse analysis which includes bodily gestures, utterances and all sort of affective expressions. 
In I-Reflexes, the idea of introducing audience participation using their mobile phones was intended to enhance the empathetic relation between the dancer (myself) and the audience. The audience's phone numbers were collected at the start of the performance and one of the musicians texted specific instructions to audience members at an agreed-moment in the piece. Instructions included: 1) ring this number xxx; and 2) play your ring tone three times.

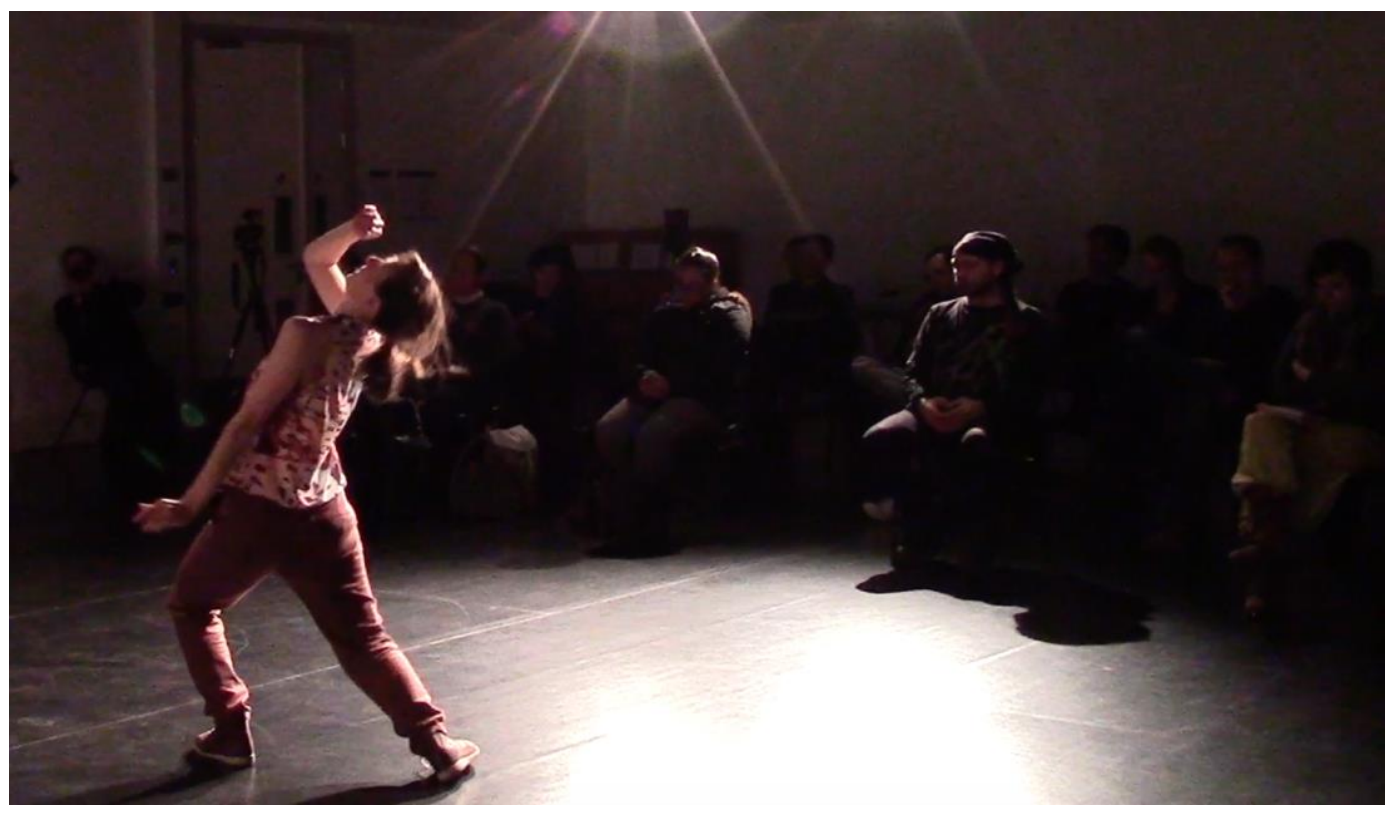

Figure 3. I-Reflexes, Brunel University, London April 2016.

At the International Meta-Body Symposium at Brunel University (London) in April 2016, we performed I-Reflexes over three consecutive nights (see video reference) for an audience of artists, scholars, and members of the public. At Brunel, the performance area was a large studio space. On this occasion, we made use of stage light, and the seating area was in the form of a thrust stage. During the first performance night, the Ethernet connection was lost, causing the musicians to get disconnected from the audience's mobile phones. Instead, the musicians emulated the audience's interaction by means of playing ringtones from their sound libraries. While I was not aware of this technical failure, in my dancing I noticed the lack of movement and physical interaction in the audience. This made me feel they were not engaged in the performance, and my responses to the soundscape became more automatic, falling into movement patterns that I recognized from the rehearsal process. This technical problem highlighted how important it was for me that the audience engaged physically with the piece. It was my perception and interpretation of the audience's gestures and actions that stimulated my attention in the earlier show and this was missing this time around. 
This made me consider how the relationship between myself as dance improviser, the audience and the performance were altered because of the lack of audience's bodily engagement. In this performance, I not only became disconnected from the sounds they created, but from their corporeal engagement with the performance; this, in turn, interrupted my experience of kinesthetic empathy with the audience. This unexpected error appeared as a fundamental moment in which the intimately interrelated nature of affect and kinesthetic empathy was revealed to me.

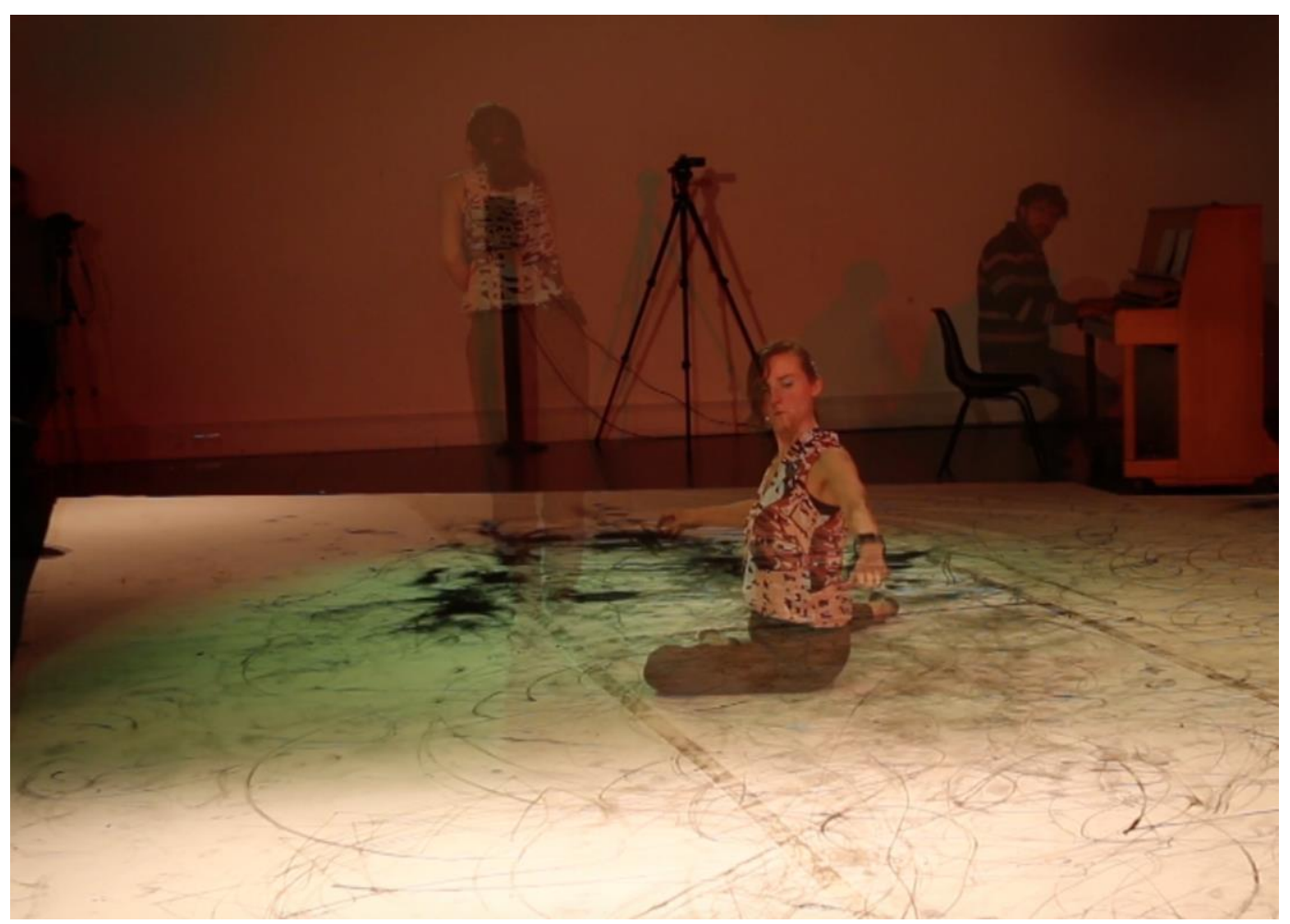

Figure 4. I-Reflexes, Brunel University, London, April 2016.

A second event supports my argument for the benefits of investigating dance improvisation from the perspective of the affective implications of kinesthetic empathy. During the last night of performance at Brunel, we introduced a new element which transformed my dance improvisation experience. During the third night of I-Reflexes at Brunel, we had incorporated the use of a mobile phone application called Sonolope. This application enables the holder of a mobile device "to generate three-dimensional sound-scapes as you move around." 15 Towards the end of this show, I wore an Apple Watch that played the sound of a violin, and musician Martin Devek improvised with me, using an acoustic piano. As I moved my left arm, a violin "played." This body and piano improvisation section offered a new experiment in which to explore the relationship between auditory stimuli and decision-making in dance improvisation. 
While movement and sound were mutually responsive, in the original set-up of the piece this new iteration created a physical disengagement with the audience. I was now making movement choices based upon musical perception and choreographic form, while at the same time I was disconnected from the audience's affective response. I lost my experience of kinesthetic empathy with the audience and I felt I was dance improvising in a customary fashion.

Thinking in terms of the affective implications of kinesthetic empathy helped me identify in what ways audience interaction influenced my decision-making in $I$ Reflexes. Building on the theoretical discussion, in this next section I reflect upon my experience as improviser of I-Reflexes, offering the development of my ideas as the intersection between performance and reflective practice.

\section{Reflections on I-Reflexes}

All five shows were performed under extremely different conditions; this offered me a multiplicity of experiences from which to reflect on my research question. My experiments in I-Reflexes were designed to explore possible factors influencing decision-making in dance improvisation. I drew from Merleau-Ponty's understanding of reflex behavior as an active response of turning towards a stimulus, and this motivated me to interrogate my performance practice by asking: what am I turning towards, when improvising in the context of a live interactive soundscape of ringtones? The process of performing in five different situations helped develop this inquiry. Unexpected failures turned into opportunities for examining the interplay of relations in each specific performance situation, and it soon became evident I was turning towards the audience's embodied presence. The qualities of their bodily gestures informed my movement response more than anything else in the room. This observation led me to investigate the notion of affect and the circulation of affect between bodies. The idea of "pulses of energetic relations" as proposed by Margaret Wetherell became useful for analyzing my experience of physical engagement and proximity to bodies in performance. While I hold a wide multisensory awareness to all the stimuli in the performative environment - and especially to ringtones - my attention was pulled towards people. Wetherell proposes a useful model for the study of affect that can contribute to advance understandings of the circulation of affect in dance improvisation practice and performance. In I-Reflexes the relational dynamic between bodies involved interaction between perceptual awareness and the affective forces of bodies in a space 
of proximity. This brought me to the conclusion that perception brings the world into the body, while affect sends the body out into the world.

The space created in I-Reflexes involved interaction between moving bodies in a performance situation (dancer, musicians and audience) mediated through the sounds of mobile devices. Altogether, this had the effect of heightening the audience's perceptual awareness, turning their attention towards the relationship between performers' movements and sounds, as well as towards their own corporeal engagement with the performance. At the end of the final show, an audience member commented: "I realized that I don't decide at all when I want to answer a call, I simply pick up my phone and start reading a text and texting back. It's only when I notice I'm annoyed, or worried by the message that I think I shouldn't have answered." 16 This comment suggests that the interactive participation in the improvisational performance amplified her kinesthetic empathy towards her own physical experience of responding to phone calls.

\section{Conclusion}

One of the major discoveries that emerge from this performance research is that interactive participation creates a closer affective encounter between performers and the audience, connecting them in a stimulating way. Within this affective encounter of forces, bodies have the capacity to influence each other in ways that can affect their interaction, informing the dance in real time. Moreover, the idea of the supra-personal nature of affect in social practices proposed by Wetherell suggests that the affective encounter in dance improvisation performance is between performers, the audience and a supra-body that is the performance. The idea of affect as "pulses of energetic relation" ${ }^{17}$ proposed by Margaret Wetherell also provides a key concept to explore how these affective encounters manifested in the performance event. This pointed me to pay attention to bodily gestures, the speed of action and the sense of rhythm created by the interactive participation. In addition, proxemics between performers and audience appeared as a significant factor, influencing decision-making in dance improvisation. The use of mobile devices and ringtones as a means for interaction had the effect of heightening the audience's perceptual awareness of the relation between performers' movements and sound, as well as deepening their own sensorial engagement with the performance - thus, the physical and perceptual interaction amplified the experience of kinesthetic empathy for both performers and participants. From this dynamic process 
of sensing and perceiving that I experienced in I-Reflexes, I suggest that affect and perception should be study together. For future research, the sonification of participation seems a productive way to address issues on disembodied action in the use of electronic communication devices. The potential of participatory interaction in improvisation performance to explore understandings of disembodied action in social practices would benefit from further research.

\section{Video Link to Performances}

https://youtu.be/zgrl5J1Wmko

https://vimeo.com/182750899

${ }^{1}$ Maurice Merleau-Ponty, Phenomenology of Perception, Translated by Donald A. Landes (New York: Routledge, 1945), 81.

${ }^{2}$ Margaret Wetherell, Affect and Emotion: A New Social Science Understanding, (London: Sage Publications, 2012), 141.

${ }^{3}$ Ibid.

${ }^{4}$ Ibid., 27.

${ }^{5}$ Ibid., 142.

${ }^{6}$ Ibid., 143.

${ }^{7}$ Susan Leigh Foster, "Taken by Surprise, Improvisation in Dance and Mind," in Taken by Surprise: A Dance Improvizatoin Reader, ed. Ann Cooper Albright and David Gere (Middletown, Connecticut: Wesleyan University Press, 2003), 8.

${ }^{8}$ Ibid., 9.

${ }^{9}$ Ibid.

${ }^{10}$ Ibid.

${ }^{11}$ John Martin, Introduction to the Dance (New York: ICA, 1965).

${ }^{12}$ Susan Liegh Foster, Choreographing Empathy: Kinesthesia in Performance (New York: Routledge, 2011).

${ }^{13}$ Elizabeth Dempster, "The Economy of Shame or Why Dance Cannot Fail," in Choreography and Corporeality: Relay in Motion, ed. Thomas F. DeFrantz and Philipa Rothfield (London: Palgrave Macmillan, 2016), 155-72.

${ }^{14}$ Dee Reynolds and Matthew Reason, eds., Kinesthetic Empathy in Creative and Cultural Practices (Bristol: Intellect Books, 2012).

15 www.sonolope.com accessed May 2017.

${ }^{16}$ Audience member comment, May 2016.

${ }^{17}$ Wetherell, 141. 